\title{
Illicit Drug Use Initiation in the Nordic Countries
}

\author{
Kim Moeller
}

Centre for Alcohol and Drug Research, School of Business and Social Science, Bartolins Allé 10, 8000 Aarhus C, Danmark

\begin{abstract}
The aim of this review is to provide an overview of the most important research into young people's initiation of illicit drug use in the Nordic countries. A systematic literature review was undertaken in Sweden, Denmark, Norway, combined with a qualified search in Finland and Iceland. The search was based on the PubMed and Sociological Abstracts databases in combination with Google Scholar. A total of 333 documents were reviewed, primarily English peer-reviewed articles, but also reports and books in the Nordic languages. 46 documents were chosen to represent the research into illicit drug initiation in the Nordic countries. The review has two parts. In the first part the typical drug initiation sequence and the different interpretations of this sequence in the Nordic countries is presented. In the second part four categories of risk factors are identified, and a review of the most significant Nordic research into these is presented. The categories are: parenting styles, emotional control, sensation-seeking behaviour, collective identitycreation processes, and risk perceptions.
\end{abstract}

Keywords: Literature review, illicit drugs, initiation, Nordic social science, risk factors.

\section{INTRODUCTION}

The Nordic countries, Denmark, Norway, Sweden, Finland, and Iceland, share many historical and socioeconomic features (Esping-Andersen 1990), but also display large variations in illicit drug use rates and drug control policies. This became clear in the 1990's where the Nordic countries simultaneously experienced an increase in the accessibility of new types of illicit drugs, higher crime rates, stricter drug legislation and intensified enforcement, referred to as the "second drug wave" (Partanen and Metso 1999). The aim of this article is to provide a systematic review of social science research into risk factors that have been identified as important for young people's initiation of illicit drug use in the Nordic countries.

The section below presents the method used for the literature search and considers some limitations of the study. The next section introduces the historical background for the study, namely the hypothetical development sequence and discusses how this has been interpreted in the theories of stepping stone and the majority fallacy.

\section{SEARCH STRATEGY AND SELECTION CRITERIA}

The search was based on the PubMed and Sociological Abstracts databases in combination with Google Scholar. Firstly the search was for articles published since 1990 on illicit drug use initiation, with

*Address correspondence to this author at the Centre for Alcohol and Drug Research, School of Business and Social Science, Bartolins Allé 10, 8000 Aarhus C, Danmark; Tel: +4587165315; Fax: +4587164420;

E-mail: km@crf.au.dk the combination of three search terms. Firstly the most common illicit drugs "cannabis", "cocaine", "amphetamine", "ecstasy", "heroin", and secondly the terms "young", "adolescent", "use", and "initiation", and finally the names of the Nordic countries "Sweden", "Norway", "Denmark", "Finland" and "Iceland". The search was subsequently copied in the library databases, Libris.se, NORART and bibliotek.dk, with a view to finding research in the Nordic languages that is abstracted in the library databases. Additional publications were identified from the books, edited works, and reports in the field. This search was combined with a qualified but not systematic search of literature in the Finnish and Icelandic languages, assisted by The Nordic Centre for Welfare and Social Issues (NVC) and the Icelandic researchers.

Relevant reports from government institutions involved in drug research were also included. From Denmark this means the National Board of Health, the Danish National Centre for Social Research (SIF) and the Centre for Alcohol and Drug Research (CRF). From Norway, the Norwegian Institute of Public Health and the Norwegian Institute for Alcohol and Drug Research (SIRUS). From Sweden, the Centre for Social Research on Alcohol and Drugs (SoRAD) at Stockholm University and the Swedish Council for Information on Alcohol and Other Drugs (CAN). From Finland, the National Institute for Health and Welfare (THL).

In total, 333 documents were found. A reference list on these studies was prepared and sent to selected researchers in each Nordic country. These researchers were selected based on considerations concerning their positions in and contributions to the field. Their comments and contributions were then included in the 
review. 46 of the reviewed documents were found to be particularly important and representative of the findings in the Nordic research and were selected for this review. Most of the selected studies were published in English peer-reviewed journals, but also books, bookchapters and reports in the Nordic languages were chosen when the topic was of particular importance.

Space constraints necessitated a reduction in the number of keywords included in the search. This study does not purport to be a comprehensive review of all research into illicit drug use initiation in the Nordic countries. The selection criteria have been to identify the most important theories on drug progression among young adults and the most important risk factors analysed in the 333 documents. When these three theories and five risk factors were identified the studies were evaluated for their international and longitudinal impact. Studies published in English high impact factor journals were given priority over local publications. Theories on escalation of drug use were evaluated according to an assessment of their relevance for the social sciences today. It has been particularly difficult to delineate prevention studies and initiation studies. A few select studies have been included that involve surveys of risk factors for young people's use of alcohol and tobacco because they also contain analysis of illicit drug use. Selected theories on drug using careers that are originally informed by alcohol use have been included when they are found to be of particular relevance, like the Majority Fallacy theory. Also, the focus on the period after 1990 is more of a prioritization than a consistent demarcation as some studies and concepts proved to very influential across longer periods of time and had to be included. Inevitably, grey areas arise.

\section{FINDINGS}

The following sections review the social science research into five types of non-drug risk factors that have been found to affect illicit drug use initiation rates in the Nordic countries: 1) parenting styles, 2) emotional control, 3) sensation seeking behavior, 4) collective identity-creation and, 5) risk perceptions.

\section{HYPOTHETICAL DEVELOPMENT SEQUENCE}

There are three patterns that are most clearly evident in the use of drugs. Firstly, prevalence is highest among young men, and secondly, it is higher in large cities. Thirdly, as regards the introduction into use there is a hierarchy of drugs from the most common to the least common. Interpreted in a pragmatic sense, this is a typical empirically observed sequence that goes as follows: alcohol, nicotine, cannabis, amphetamines, cocaine, ecstasy, and heroin. Only a small minority start with illicit drugs (Pedersen and Skrondal 1999; Pedersen and Skrondal 1998).

The sequence is crucial for understanding young people's development of drug use because an early start for using alcohol, cigarettes and cannabis is correlated with an increased risk of problematic use of alcohol and cannabis later in life. Pedersen's longitudinal study "Youth, Lifestyle, and Drugs" (Pedersen 1990; Pedersen 1991a) documents this. In summary, Pedersen (1998) notes that particularly an early début for cigarette smoking is strongly correlated with the use of illicit drugs in adulthood. The figures in brackets show the estimated explanatory effect that an early smoking début has on the development in later use of other drugs. Early smoking début increases chances of smoking in adulthood, but also alcohol problems (3:1), use of cannabis (3:1) and use of other illicit drugs (4:1). Secondly, early cannabis use is also a powerful predictive indication for later development of both alcohol problems (5:1), sustained cannabis use (3.6:1) and use of other illicit drugs (e.g. amphetamines, cocaine, etc.) (12:1). This hypothetical development sequence offers no theoretical explanation for this progression in drug using careers.

\section{THE STEPPING STONE EFFECT}

The stepping stone effect describes how using one type of drug increases the risk of using another and more harmful drug, and that this risk increases with the frequency of use (Bretteville-Jensen Jacobi 2010). The central question is whether this is merely a correlation with the underlying risk factors or whether the various types of drug use are somehow causally connected? The empirical basis for formulating the theory was an interpretation of the hypothetical development sequence. Kandel (1975) posed three questions that have still not been clarified today. Should we interpret the development sequence to imply that using one type of drug improves access to other types of drugs? Is the tendency to progress to new drugs due to a psychological and/or physiological urge to experience more powerful intoxication? Are social and group dynamic processes the deciding factors? The stepping stone effect is disputed but has had a considerable influence on shaping drug policies in the Nordic countries over the years. In Norway and Sweden the drug control policies have focused on deterring young 
people from initiating cannabis use (Hakkarainen, Jetsu, and Laursen 1996). In Denmark the focus has been to keep the markets for cannabis and other drugs separate (Storgaard 2000). Norway and Sweden focus on the potential for a psychological and physiological effect, while Denmark has focused on the social and group dynamic processes involved in illicit drug use.

In a number of quantitative studies, BrettevilleJensen and colleagues used various regression models (a latent class bivariate hazard model (Bretteville-Jensen 2006), Bayesian degenerate sample selection analysis (Bretteville-Jensen and Jacobi 2010) and multivariate probit analysis (Bretteville-Jensen and Melberg 2008)) and found documentation supporting a stepping stone effect. A later study stated more precisely that a small group of maladjusted young people exhibited a significant stepping stone effect. For another group of welladjusted young people in the study, cannabis use did not influence future use of other drugs (Melberg, Jones, and Bretteville-Jensen 2010). In a survey of 13-19year-old Norwegian cannabis users, Pedersen (1990) found that most stopped using cannabis again after very few times. The relative weights of the stepping stone effect, individual propensity and access to drugs, respectively, are not agreed upon (Bretteville-Jensen and Jacobi 2010). The finding by Melberg, Jones and Bretteville-Jensen (2010) suggests that underlying problem behaviour is quite important for future drug use by young adults as compared to relative explanatory weight of the stepping effect and access to drugs. This is important for the discussion raised by Pedersen $(1990,1998)$ as to the explanatory effect of early smoking début on later drug use.

\section{MAJORITY FALLACY}

A social contagion effect does exist between young people. Christie and Hauge (1962) documented how young people tend to overestimate the alcohol consumption of their peers. They argue that incorrect perceptions of other young people's behaviour and delinquency can arise in groups with superficial acquaintances. The phenomenon was termed "the great majority fallacy" and it was feared that youth would experience a misunderstood group pressure to drink more alcohol. The extent to which this social pressure actually increases illicit drug use is not documented (Pedersen 1993), but the social processes involved are relevant to the understanding of why young people use drugs.
We know that socially inclined young people tend to drink more than average, or alternatively, that young people who drink more than average are socially inclined (Fekjær and Pape 2004; Järvinen and Gundelach 2007). At the early stages of experimental and recreational use, illicit drug consumption is a social activity. In this way, the high-consuming young people can become reference individuals for a disproportionate number of people. They are said to have an "asymmetrical attachment", which explains why young people overestimate how much "others" use (Pedersen 1993). In a nationwide survey among Norwegian 15-20-year-olds, young people were found to seriously overestimate their peers' experience with cannabis, ecstasy and amphetamines. The difference between the actual and assumed rates of prevalence was greatest in relation to ecstasy and amphetamines, which Fekjær and Pape (2004) interpret as a result of the "massive and misleading media coverage" given to these drugs when they were first introduced in the early 1990's.

\section{PARENTING STYLES}

In a study of 347 young people in Iceland, Adalbjarnardottir and Hafsteinsson (2001) found that parenting style had a major influence on young people's use of intoxicants. The respondents were part of a larger survey of 1,293 people and it was the young people themselves that characterised their parents' style of parenting, from a combination of two dimensions, support and control. The dimension of support consists of acceptance and benevolence, while control comprises strictness and demands. The combination resulted in four prototypical parenting styles: Authoritative parents are both accepting and demanding, in other words supportive but with clear standards for their children's behaviour; Standards that they take the time to explain. Authoritarian parents are characterised by being demanding and controlling but not warm. They set clear rules that cannot be questioned. Lenient parents are described as benevolent and warm but less demanding. They allow an extensive degree of self-regulation and avoid confrontation. Negligent parents are neither benevolent nor demanding. They neither supervise nor support their children. The respondents were questioned at the age of 14 and again at the age of 17. Adalbjarnardottir and Hafsteinsson (2001) found that there was a link between the parenting and the use of drugs. The link was apparent at both temporal points, i.e. cross sectional at 14-year-old and again as 17-year-old. The result was independent of both the parents' and friends' 
use of drugs and the young people's previous use. The correlation was apparent for both boys and girls. Similar results have been found in Finland (Ahlström, Metso, and Tuovinen 2003).

\section{EMOTIONAL CONTROL}

Stenbacka, Allebck, and Romelsjö (1992) analysed the use of cannabis and intravenous heroin, respectively, in a cohort of 8,168 conscripted Swedish men aged 18-20 in 1969-70, in order to examine various risk factors associated with use of the different illicit drugs. Specifically they wanted to identify risk factors among heavy users of cannabis who would later go on to use heroin. A multivariate regression analysis used the parents' social status and alcohol consumption, the young people's contact with the police, alcohol consumption, use of solvents and crime. These risk factors were divided into two categories: social risks and personal emotional control. The identification of intravenous users was part of a routine registration of needle marks in all people brought in to the central arrest facility in Stockholm. Stenbacka et al. (1992) interviewed the people with needle marks about the age at which they had started taking drugs, types of drugs and frequency of use. Of the 8,168 conscripted young men in the cohort, 97 (1.2 percent) were later found in the "needle mark study". An additional 91 conscripted young men stated that they had used heroin intravenously as 18-20-year-olds but did not appear later in the authorities' criminal registers. A total of 1,446 stated that they were heavy users of cannabis. Stenbacka et al. (1992) found that all the users of illicit drugs were more socially vulnerable than the group of conscripted young men seen as a whole. Especially a low degree of emotional control was associated with increased risk of developing intravenous addiction. In terms of cannabis addiction, the personal emotional risk factors were more important than the social factors. Almost half of the intravenous drug addicts who were later registered had been in contact with the police or juvenile authorities. The same applied for only 3.9 percent of heavy users of cannabis.

In a subsequent study of a cohort of 23,482 Swedish men conscripted between 1969 and 1970, Stenbacka, Allebeck, and Rafnsson (1993) analysed the correlations between family background, social factors, use of legal drugs, emotional control and drug using career. Drug using career was defined as three points: the first time the person was offered drugs, first use of cannabis and first injecting drug use. Their study showed that deviant social behaviour such as running away from home and truancy were stronger explanatory factors for intravenous drug use than both heavy use of cannabis, alcohol addiction and tobacco smoking (Stenbacka et al. 1993), similar to the finding by Melberg, Jones and Bretteville-Jensen (2010).

Adalbjarnardottir and Rafnsson (2002) found that among 1,293 14-year-old non-users of drugs in Iceland, a link was evident between antisocial behaviour and subsequent use of drugs. Antisocial behaviour can be e.g. disobedience at school, fighting and vandalism. The antisocial 14-year-olds were more likely to smoke tobacco daily and have experimented with cannabis and amphetamines at the age of 17 . The causality is unclear, however, and the authors refer to another study that shows the opposite sequence, i.e. that early use of drugs is linked to later antisocial behaviour. Pedersen and Skardhamar (2009) found that early cannabis use was correlated with subsequent registered criminal charges, but that most of this crime was drug related. The predictions for non-drug crimes were found to be non-significant after controlling for prior risk factors.

Other studies have found that diagnosed psychiatric conduct disorders are linked to later use of drugs, lower initiation age for drug use and an increased risk of developing drug problems (Pedersen, Mastekaasa, and Wichstrøm 2001). According to DSM-IV, such conduct disorders could be: threatening others, fighting, vandalism, stealing, committing burglary and truancy from school. Korhonen et al. (2010) challenge the assumption that externalizing behaviour problems such as in DSM-IV explains later use of cannabis. Firstly the correlation between such conduct and later cannabis use is unequal between the sexes, and secondly it is often mediated by tobacco smoking. Korhonen et al. (2010) conclude that early tobacco smoking reveals more about a later risk of cannabis use than behavioural problems.

\section{SENSATION SEEKING BEHAVIOUR}

There are different types of high-risk behaviour found among young people. The common denominator is referred to as "sensation seeking" which covers behaviour characterised by a search for adventure and new experiences. This is typically linked to living in an urban environment and having a low degree of parental supervision (Arnett and Balle-Jensen 1993).

Pedersen (1991a; 1991b; 1996) analysed the correlations between personality traits and use of drugs. Their starting point was an abbreviated version 
of Zuckerman's (1979) scale of 40 sensation-seeking traits. They found sensation seeking to have a moderate to strong correlation with the use of drugs among 1,027 Norwegian schoolchildren aged 16 to 19 . The more common and accepted the type of drug, the weaker the correlation with a sensation-seeking personality (Pedersen 1991b). For example, sensation seeking is linked to high alcohol consumption in young women aged between 16 and 19 but not in young men. Pedersen (1996) specifies four subdimensions of sensation-seeking traits that are linked to drug use: Thrill and adventure seeking (TAS), Disinhibition (DIS), Experience-seeking (ES) and Boredom susceptibility (BS). In particular, the DIS-scale is strongly correlated with all forms of illicit drug use for both sexes, which is consistent with how drugs are used to remove social inhibitions in western cultural circles. While young people's mental health fluctuates over time, it appears that a sensation seeking personality trait is stable. Hakkarainen and Metso (2004) point out that young people today appear to live in a more consumptionoriented culture where enjoyment and extreme experiences are in demand. Experimental use of drugs therefore gains new importance as an experience with (more or less) controlled risk taking.

\section{COLLECTIVE IDENTITY-CREATION PROCESSES}

Identity is a central concept for understanding young people's actions in relation to the use of drugs. Identity is a concept linked to the person's experienced attachments based on age, sex and social class. As traditional social structures fade, young people can no longer turn to predefined roles for support. This means that the importance of collective identity creation increases (Pedersen 1998).

The transition from childhood to adulthood is particularly important in relation to social identity creation. The use of drugs can act as a symbolic identity marker, through which young people communicate maturity to their friends (Demant and Järvinen 2006). Drugs are associated with that which is adult, dangerous and forbidden, and they also are associated with various transitions (from everyday life to parties, from work to play and with major rites of passage such as confirmation, leaving school, etc.). In this way, drug use is ritual behaviour. Young people communicate symbolically with each other and the outside world when they use drugs (Pedersen 1994). Sato (2004) describes how stories about parties and drug use are given major symbolic meaning as reference points for groups of young people. The drugs symbolise a "ritual of brotherhood" that creates unity and identity. These rituals constitute a situation-based risk taking. Hesse, Tutenges, and Schliewe (2010) describe how music festivals can play a role in introducing young people to illicit drugs, and others have shown how the club culture can be a pivotal point for young people's subcultural identity and illicit drug use (Demant, Ravn, and Thorsen 2010; Salasuo and Seeppälä 2004; Salasuo 2004; Sjö 2005).

Kouvonen and Lintonen (2002) analysed 47,568 Finnish young people aged 14.3 to 16.2 years who either worked more than ten hours a week or had an "adult-like" job at a restaurant or cleaning. They found that these young people were overrepresented among those using drugs more than five times a week, including alcohol. It was not possible for the researchers to ascertain whether this is a special selection of young people, or whether a socialisation process is taking place in connection with the work. Pedersen (1991a) found that boys who seek out environments where the use of cannabis is common, and who have personality traits that are predisposed towards cannabis use, will over time develop into cannabis users. The difference between cannabisusing and non-cannabis-using young people in a highrisk environment was that the users came from "incomplete" families and were men (Hammer and Vaglum 1990; Hammer 1992). A similar phenomenon applies to unemployment. For the population as a whole, unemployment does not lead to cannabis use, but unemployment increases the chance of continuing an already existing cannabis use (Hammer 1992).

\section{RISK PERCEPTIONS}

Attitudes towards illicit drugs are linked to personal experience, attitudes in society at large, and the symbolic value attached to the drugs. Finnish young people aged between 14 and 16 were asked about their motivation for using alcohol and other drugs, in $1984(\mathrm{~N}=396)$ and in 1999 ( $\mathrm{N}=488)$. In the later study, a larger number highlighted that alcohol and other drugs were "fun", and fewer emphasised the negative consequences. Some researchers interpret this as an expression of increased egoism in young Finn's value sets (Palmqvist, Martikainen, and Rauste 2003).

Hakkarainen, Tigerstedtm and Tammi (2007) found that half of the Finns less than 35 years of age asses only a "slight" or "no risk" from with experimenting with cannabis, whereas older people are far more critical. Sato (2004) conducted an interview survey and found 
that the boys thought cannabis use is "completely okay" while you are young. Later in life however, cannabis use is perceived as incompatible with career aspirations and self-realisation. Bjarnason, Steriu, and Kokkevi (2010) similarly found that young people who perceived cannabis as harmful were less likely to have used cannabis within the past 30 days, and vice versa.

Ideally such findings would be connected with analysis of wider societal trends in the regulation of illicit drugs. Individuals, subgroups and society interact in a variety of ways that can and will change over time. Pedersen (1990) describes how the use of cannabis over a long period has changed character as a societal phenomenon. Cannabis users in the 1960s were characterised as predominantly resourceful young people from the middle class with a normative conflict with society that they had chosen to take upon themselves. In the 1970s, it became more normal for young people from the lower social classes to use cannabis. Some of these had social problems other than drug use. In a study of 1,311 Norwegian schoolchildren aged between 13 and 19, Pedersen (1991b) found that the group involved in experimental use was still characterised by a normative conflict of interests with society, while the heavy users also had family-based problems and poor mental health. Again, this supports the notion that underlying problem behaviour is an important correlate for developing problematic use (Melberg, Jones and BrettevilleJensen 2010).

Society's formal condemnation of illicit drugs is expressed in the legal regulation. The Nordic countries' drug control policies can be said to rely on a deterrent theory that is based on three (microeconomic) mechanisms (Bretteville-Jensen 2006): accessibility, price and risk of punishment. Both accessibility and price are affected by the risk of punishment. The authorities can adjust the risk of punishment through the control policy, which is thereby assumed to indirectly influence the use of intoxicants, as the control policy influences how young people assess the risk and accessibility of various intoxicants. Bjarnason et al. (2010) conclude that future research should analyse how accessibility and risk perception are linked to the level of cannabis use among young people in various countries and how the different control policies affect this.

\section{FINAL SUMMARY}

Social science research in the Nordic countries has indentified a series of risk factors and social processes that are of importance in order to understand why some young people initiate illicit drug use. 333 peer-reviewed articles, books, and reports were studied in order to assess the state of Nordic research. 48 of these studies were found to contain the most significant findings. These were been grouped together and presented in the present article. The time period after 1990 signalled what has since come to be known as the "second drug wave" (Partanen and Metso 1999) which has involved hitherto new levels of illicit drug use, a wider variety of drugs being used, and a series of new social contexts in which specific drugs have gained a subcultural meaning.

A series of longitudinal studies demonstrate which combinations of risk factors are the most relevant for predicting future problematic drug use. Some of these studies find that the early use of tobacco is probably the strongest indicator for developing problematic drug use later in life, followed by early cannabis use. Other studies find that underlying problem behaviour is more important. This issue is actively debated to this day.

Adalbjarnardottir and Hafsteinsson (2001) conclude by pointing out that the culture in a small isolated country like Iceland is very restrictive and condemnatory towards illicit drugs, which supports the deterrent mechanisms of the formal control policy. Future comparative research on the developments in different countries can potentially inform us on this but the intricacies of national level policies complicate such an endeavour.

\section{REFERENCES}

Adalbjarnardottir, Sigrun and Leifur G. Hafsteinsonn. 2001. "Adolescents' perceived parenting styles and their substance use: Concurrent and longitudinal analyses." Journal of Research on Adolescence 11: 401-423. http://dx.doi.org/10.1111/1532-7795.00018

Adalbjarnardottir, Sigrun and Fjolvar D. Rafnsson. 2002. "Adolescent antisocial behavior and substance use Longitudinal analyses". Addictive Behaviors 27: 227-240. http://dx.doi.org/10.1016/S0306-4603(00)00179-9

Ahlström, Salme, Leena Metso, and Eeva Liisa Tuovinen. 2003. "Mikä lisää nuoren riskiä tupakoida, humaltua ja kokeilla marihuana? [Which Factors Increase the Risk of Youth Smoking, Drinking and Experimenting with Marijuana?]." Yhteiskuntapolitiikka 68: 597-602.

Arnett, Jeffrey and Lene Balle-Jensen. 1993. "Cultural Bases of Risk Behavior: Danish Adolescents." Child Development 64: 1842-1855.

http://dx.doi.org/10.2307/1131473

Bjarnason, Thoroddur, Andreea Steriu, and Anna Kokkevi. 2010. "Cannabis supply and demand reduction: Evidence from the ESPAD study of adolescents in 31 European countries." Drugs: Education, Prevention and Policy 17: 123-134. http://dx.doi.org/10.3109/09687630802419155 
Bretteville-Jensen, Anne Line. 2006. "Drug Demand - Initiation, Continuation and Quitting." De Economist 154: 491-516. http://dx.doi.org/10.1007/s10645-006-9027-9

Bretteville-Jensen, Anne Line, and Liana Jacobi. 2010. "Climbing the Drug Staircase: A Bayesian Analysis of the Initiation of Hard Drug Use." Journal of Applied Economics 26: 1157-1186. http://dx.doi.org/10.1002/jae.1160

Bretteville-Jensen, Anne Line, Hans O. Melberg, and Andrew Jones. 2008. "Sequential Patterns of Drug Use Initiation - Can We Believe In the Gateway Theory?" The B.E. Journal of Economic Analysis \& Policy 8: 1-29. http://dx.doi.org/10.2202/1935-1682.1846

Christie, Nils and Ragnar Hauge. 1962. "Alkoholvaner blant storbyungdom [Alcohol Use among City Youth]." Oslo: Universitetsforlaget.

Demant, Jakob and Margaretha Järvinen. 2006. "Constructing Maturity through Alcohol Experience. Focus Groups with Teenagers." Addiction Research and Theory 14(6): 589-602. http://dx.doi.org/10.1080/16066350600691683

Demant, Jakob, Signe Ravn, and Sidsel Thorsen. 2010. "Club studies: methodological perspectives for researching drug use in a central youth social space." Leisure Studies 29(3): 241-252.

http://dx.doi.org/10.1080/02614360903071712

Esping-Andersen, Gøsta. 1990. "The Three Worlds of Welfare Capitalism." London: Polity Press.

Fekjær, Silje and Hilde Pape. 2004. "Når 'alle' doper seg - Feilaktige forestillinger om narkotikabruk blant ungdom [When 'Everybody' is High - Misconceptions of Drug Use among Youth]." Tidsskrift for Ungdomsforskning 4: 21-32.

Hakkarainen, Pekka and Leena Metso. 2004. "Finländarnas inställning till narkotika och narkotikapolitiken [Finn's Attitudes to Drug and Alcohol Policies]." Nordisk alkohol- \& narkotikatidsskrift 21: 41-54.

Hakkarainen, Pekka, Christoffer Tigerstedt, and Tuukka Tammi. 2007. "Dual-track drug policy - Normalization of the drug problem in Finland." Drugs: Education, Prevention and Policy 14: 543-558. http://dx.doi.org/10.1080/09687630701392008

Hakkarainen, Pekka, Timo Jetsu, and Lau Laursen. 1996. "The legal framework and the drug control system." Pp. 21-32 in Discussing Drugs and Control Policy, edited by P.Hakkarainen, L. Laursen, and C. Tigerstedt. Helsinki: Nordic Council for Alcohol and Drug Research.

Hammer, Torild and Per Vaglum. 1991. "Users and Nonusers within a High Risk Milieu of Cannabis Use. A General Population Study." Substance Use and Misuse 26: 595-604. http://dx.doi.org/10.3109/10826089109058907

Hammer, Torild and Per Vaglum. 1990. "Initiation, continuation or discontinuation of cannabis use in the general population." British Journal of Addiction 85: 899-909. http://dx.doi.org/10.1111/j.1360-0443.1990.tb03720.x

Hammer, Torild. 1992. "Unemployment and use of drug and alcohol among young people: a longitudinal study in the general population." British Journal of Addiction 87: 1571-81. http://dx.doi.org/10.1111/j.1360-0443.1992.tb02665.x

Hesse, Morten, Sebastien Tutenges, and Sanna Schliewe. 2010. "The Use of Tobacco and Cannabis at an International Music Festival." European Addiction Research 16: 208-212. http://dx.doi.org/10.1159/000317250

Järvinen, Margaretha and Peter Gundelach. 2007. "Teenage Drinking, Symbolic Capital and Distinction." Journal of Youth Studies 10: 55-71. http://dx.doi.org/10.1080/13676260701196137

Kandel, Denise B. 1975. "Stages in adolescent involvement in drug use." Science 190: 912-914. http://dx.doi.org/10.1126/science.1188374
Korhonen, Tellervi, Andrea Prince Leeuwen, Sijmen A von Reijneveld, Johan Ormel, Frank C. Verhulst, and Anja C. Huizink. 2010. "Externalizing Behavior Problems and Cigarette Smoking as Predictors of Cannabis Use: The TRAILS Study." Journal of the American Academy of Child and Adolescent Psychiatry 49: 61-69.

Kouvonen, Anne and Tomi Lintonen. 2002. "Adolescent work and drug experiments." Journal of Substance Use 7: 85-92. http://dx.doi.org/10.1080/14659890210132117

Melberg, Hans Ole, Andrew M. Jones, and Anne Line BrettevilleJensen. 2010. "Is cannabis a gateway to hard drugs?" Empirical Economics 38: 583-603. http://dx.doi.org/10.1007/s00181-009-0280-z

Palmqvist, Riia A., Liisa K. Martikainen, and Maijaliisa Rauste. 2003. "A Moving Target: Reasons Given by Adolescents for Alcohol and Narcotics Use, 1984 and 1999." Journal of Youth and Adolescence 32: 195-203. http://dx.doi.org/10.1023/A:1022595403818

Partanen, Juha and Leena Metso. 1999. "Suomen toinen huumeaalto [The second drug wave in Finland]." Yhteiskuntapolitiikka 64: 143-149.

Pedersen, Willy. 1990. "Adolescents initiating cannabis use: cultural opposition or poor mental health?" Journal of Adolescence 13: 327-339.

http://dx.doi.org/10.1016/0140-1971(90)90027-5

Pedersen, Willy. 1991a. "Drugs in adolescent worlds: A longitudinal study of adolescent drug use socialization." Oslo: Institutt for Psykiatri, Oslo Universitet.

Pedersen, Willy. 1991b. "Mental health, sensation seeking and drug use patterns: a longitudinal study." British Journal of Addiction 86: 195-204. http://dx.doi.org/10.1111/j.1360-0443.1991.tb01769.x

Pedersen, Willy. 1993. "The Majority Fallacy Reconsidered." Acta Sociologica 36: 343-355. http://dx.doi.org/10.1177/000169939303600403

Pedersen, Willy. 1994. Ungdom er bare et ord [Youth is just a Word]. Oslo: Universitetsforlaget.

Pedersen, Willy. 1996. "Working class boys at the margins: prejudice, cultural capital and gender." Acta Sociologica 39: 257-279. http://dx.doi.org/10.1177/000169939603900301

Pedersen, Willy. 1998. Bittersøtt - Ungdom/sosialisering/rusmidler [Bittersweet - Youth/Socialisation/Drugs]. Oslo: Universitetsforlaget.

Pedersen, Willy and Torbjørn Skardhamar. 2009. "Cannabis and crime: findings from a longitudinal study." Addiction 105: 109118.

http://dx.doi.org/10.1111/j.1360-0443.2009.02719.x

Pedersen, Willy and Anders Skrondal. 1998. "Alcohol debut: predictors and consequences." Journal of Studies on Alcohol 59: 32-42.

Pedersen, Willy and Anders Skrondal. 1999. "Ecstasy and new patterns of drug use: a normal population study." Addiction 94: 1695-1706. http://dx.doi.org/10.1046/j.1360-0443.1999.941116957.x

Pedersen, Willy, Arne Mastekaasa, and Lars Wichstrøm. 2001 "Conduct Problems and Early Cannabis Initiation: A Longitudinal Study of Gender Differences." Addiction 96: 415-431. http://dx.doi.org/10.1046/j.1360-0443.2001.9634156.x

Salasuo, Mikko and Pauliina Seeppälä. 2004. "Drug use within the Finnish club culture as marks of distinction." Contemporary Drug Problems 31: 213-229.

Salasuo, Mikko. 2004. "Huumeet ajankuvana. Huumeiden viihdekäytön kulttuurinen ilmeneminen Suomessa [Drug use as zeitgeist. Recreational drug use in Finland]." Rapport Vol. 149. Helsinki: STAKES 
Sato, Hanako. 2004. "Droger och identitetsskapande - kulturelle perspektiv på alkohol och narkotika i svenska ungdomsgrupper [Drugs and Identity Creation - Cultural Perspectives on Alcohol and Drugs in Swedisk Youth Groups]." Rapport Vol 23. Stockholm: SoRAD - Centrum för socialvetenskapelig alkohol- och drogforskning.

Sjö, Fabian. 2005. "Drugs in Swedish Club Culture - Creating Identity and Distance to Mainstream Society." Pp. 31-46 in Drugs \& Youth Cultures - Global and Local Expressions, Vol. 46, edited by P. Lalander and M. Salasuo. Helsinki: Nordic Council for Alcohol and Drug Research.

Stenbacka, Marlene, Peter Allebeck, and Anders Romelsjö. 1992.

"Do cannabis drug abusers differ from intravenous drug abusers? The role of social and behavioural risk factors." British Journal of Addiction 87: 259-266.

http://dx.doi.org/10.1111/j.1360-0443.1992.tb02700.x
Stenbacka, Marlene, Peter Allebeck, and Anders Romelsjö. 1993 "Initiation into drug abuse: The pathway from being offered drugs to trying cannabis and progression to intravenous drug abuse." Scandinavian journal of Public Health 21: 31-39. http://dx.doi.org/10.1177/140349489302100106

Storgaard, Lau L. 2000. "Konstruktionen af dansk narkotikakontrolpolitik [The Construction of Danish Drug Control Policy]." Copenhagen: Dansk Jurist- og Økonomforbunds forlag.

Zuckerman, Marvin. 1979. Sensation Seeking. Hillsdale, NJ: Lawrence Erlbaum.

Received on 19-02-2013

Accepted on 15-04-2013

Published on 23-04-2013

DOI: http://dx.doi.org/10.6000/1929-4409.2013.02.8

(c) 2013 Kim Moeller; Licensee Lifescience Global.

This is an open access article licensed under the terms of the Creative Commons Attribution Non-Commercial License (http://creativecommons.org/licenses/by-nc/3.0/) which permits unrestricted, non-commercial use, distribution and reproduction in any medium, provided the work is properly cited. 